\title{
Prevalence of Shigella among diarrheic children under- 5 years of age attending at Mekelle health center, north Ethiopia
}

\author{
Atsebaha Gebrekidan Kahsay ${ }^{{ }^{*}}$ and Zelalem Teklemariam²
}

\begin{abstract}
Background: Shigellosis is recognized as a major global public health problem especially in developing countries particularly in children under-5 years of age. Therefore; the objective of this study was to determine the prevalence of Shigella among diarrheic children under-5 years of age attending at Mekelle health center, north Ethiopia.

Methods: A cross-sectional study was conducted among diarrheic children under-5 years of age from March to May, 2012. Structured questionnaire was used to collect the data. Study participants were recruited by convenience sampling technique. Shigella was isolated and identified using standard bacteriological techniques.

Results: A total of 241 study participants were included in the study. The overall prevalence of Shigella in this study was $13.3 \%$ (32/241). High prevalence of Shigella (22.6\%) was revealed from the age group of 12-23 months. No Shigella was isolated from the age group of $0-5$ months. Majority of the isolates of Shigella were from bloody and mucoid diarrhea.

Conclusion: There was high prevalence of Shigella infection in this study. Children among the age group of 12-23 months were highly affected. Therefore; responsible bodies should work hard on preventive measures to reduce or eradicate the problem occurred due to shigellosis.
\end{abstract}

Keywords: Shigella, Children under-5 years of age, Diarrhea, Mekelle health center

\section{Background}

Shigellosis is one of the main public health problems throughout the world. More than $99 \%$ of the world annual episodes of Shigella (with 1.1 million deaths) were reported from developing countries. About $69 \%$ of the world annual episodes and $61 \%$ of all the deaths were shown in children under-5 years of age [1]. High incidence rates of Shigella infection were also revealed among children under-5 years of age in United States of America [2], Europe [3] and six Asian countries (China, Thailand, Vietnam, Pakistan, Bangladesh and Indonesia) [4]. The occurrence of Shigellosis in Canada was shown in increasing order from 1.8/100,000 in 2009 to 2.82/100,000 in 2012 [5].

\footnotetext{
*Correspondence: atseba_mu@yahoo.com

${ }^{1}$ Department of Microbiology and Immunology, Institute of Biomedical Sciences, College of Health Sciences, Mekelle University, P.O. Box: 1871, Mekelle, Tigray, Ethiopia

Full list of author information is available at the end of the article
}

Shigella was reported by the Multisite birth cohort study (MAL-ED) as one of the most causative agent of the second life of children in developing countries [6]. It was also described by the Global Enteric Multi-central Study (GEMS) as one of the four contributing agents (rotavirus, Cryptosporidium, enterotoxigenic Escherichia coli-ST-ETEC) of moderate to severe diarrhea among children under-5 years in Sub Saharan Africa [7].

The prevalence of Shigella in children under-5 years of age was variable from country to country. Half of the positive isolates of Shigella in one study in China [8] and about 79 \% in Eastern Nepal [9] were shown among children under- 5 years of age. The positivity rate of Shigella in Brazil [10] among 6-24 months and in China [11] among 3-4 years was $73 \%$ and $32 / 1000 /$ year respectively. Nearly half of the positive isolates of Shigella revealed from Eritrea were among children under-5 years of age [12]. The proportion of Shigella in Mucus, bloody and 
watery diarrhea was 53, 30 and $17 \%$ respectively as indicated in the study in Central Republic of Africa [13].

The prevalence of Shigella in Ethiopia: Hawassa, Gondar, and Jimma was 7 [14], 4.57 [15] and $2.3 \%$ [16] respectively. The positivity rate of Shigella, carried out in Gondar, among children under-5 years of age was $31.1 \%$ [17].

An estimation of 133,000 annual episodes of diarrhea was reported from 2 months to 5 years children in Mekelle city. Above $38 \%$ of the episodes reported from children in Mekelle city contained blood in their stool [18]. There was not published study on the magnitude of Shigella which causes diarrhea in Mekelle city. Therefore this study tried to determine the prevalence of Shigella among children under- 5 years of age attending at Mekelle health center, north Ethiopia.

\section{Methods}

\section{Study area and period}

Mekelle is the capital city of Tigray regional state which is located $784 \mathrm{~km}$ north of Addis Ababa. It is with a total population of 261,000 [19]. This study was conducted among diarrheic children under- 5 years of age attending at Mekelle health center from March to May, 2012.

\section{Exclusion criteria}

Children under- 5 years of age who were critically ill or under antibiotic taking for diarrhea during the period of sample collection were excluded from the study.

\section{Sample size determination}

Sample size was calculated using single proportion formula by taking $(\mathrm{P}=0.195)$ [20], $5 \%$ margin of error, and $\mathrm{Z} \alpha / 2=1.96$ for $95 \%$ level of confidence.

$$
\mathrm{n}=\frac{(\mathrm{Z} \alpha / 2)^{2} \times \mathrm{P}(1-\mathrm{P})}{\mathrm{d}^{2}}=241
$$

\section{Sampling technique}

Consecutive study participants having diarrhea were recruited using convenience sampling technique.

\section{Data collection and laboratory processing}

Data on child characteristics were collected using pretested structured questionnaire from his/her parent or guardian. Then, they were instructed to provide stool sample of their child. Stool samples were collected by using sterile, wide, clean leak proof container and transported in cold box within $3 \mathrm{~h}$ to the Microbiology laboratory of Mekelle University.

\section{Culture and biochemical tests}

Stool specimens were inoculated directly on to MacConkey agar (Oxoid, England) and xylose lysine deosxycholate agar (Oxoid, England) and incubated at $37^{\circ} \mathrm{C}$ for $24 \mathrm{~h}$ to isolate Shigella. Colorless colonies from MacConkey Agar and pink colonies from xylose lysine deosxycholate agar were considered non-lactose fermenting colonies. Typical non lactose fermenting colonies were subjected to standard biochemical tests to identify Shigella. Biochemical tests were conducted on Kligler iron agar (KIA), Motility indole lysine medium, Simon's citrate agar and urea. Non lactose fermenting isolates (Red slant and yellow butt) that gave negative results for gas and hydrogen sulfide on KIA, nonmotile, urea-negative, citrate negative, lysine decarboxylase and lysine deamination negative organisms were identified as Shigella [21].

\section{Statistical analysis}

Data were entered, cleaned and analyzed using Statistical Package for Social Science (SPSS) 16. The Chi square test results were used to compare the prevalence of Shigella in different variables. $\mathrm{P}<0.05$ at $95 \%$ confidence interval was considered as statistically significant.

\section{Ethical consideration}

Ethical clearance was obtained from Haramaya University, Colleges of Health and Medical Sciences, Department of Medical laboratory Sciences, Ethical Review Committee. Permission to conduct this study was obtained from Mekelle zone health office and Mekelle health center. Assent was taken from children's parents or guardians after they understood the purpose of the study.

\section{Results}

\section{Characteristics of the study participants}

A total of 241 diarrheic children under-5 years of age were participated in this study. One hundred thirty-four $(55.6 \%)$ of the study participants were males. The highest and lowest age group participated in the study were $0-5$ $(5.8 \%)$ and $36-59(28.2 \%)$ months respectively.

The mean age of the study participants was 3.43 with $\mathrm{SD} \pm 1.26$. The duration of diarrhea shown among the study subjects was from 1 to 14 days. Majority (65.6\%) of the study participants contained blood and mucus in their stool. About $38.6 \%$ of the study participants came to the health center within 1 day of diarrhea (Table 1 ).

\section{Prevalence of Shigella}

The prevalence of Shigella in this study was $13.3 \%$ $(32 / 241)$. No Shigella was isolated from the age group of $0-5$ months. The lowest (3.9 \%) and highest (22.6\%) Shigella isolates in this study were revealed from the age group of 6-11 and 12-23 months respectively, $(\mathrm{P}<0.05)$. Isolates of Shigella were high among females than males $(\mathrm{P}>0.05)$. The highest prevalence of Shigella was shown among the study participants having bloody and mucoid 
Table 1 Prevalence of Shigella among diarrheic children under-5 years of age attending at Mekelle Health Center, North Ethiopia from March to May, 2012

\begin{tabular}{|c|c|c|c|}
\hline Variables & $\begin{array}{l}\text { Positive, } \\
\text { no (\%) }\end{array}$ & $\begin{array}{l}\text { Negative, } \\
\text { no (\%) }\end{array}$ & $\mathbf{P}$ \\
\hline \multicolumn{4}{|l|}{ Age (in months) } \\
\hline $0-5$ & $0(0)$ & $14(100)$ & \multirow[t]{5}{*}{0.029} \\
\hline $6-11$ & $2(3.9)$ & $49(96.1)$ & \\
\hline $12-23$ & $14(22.6)$ & $48(77.4)$ & \\
\hline $24-35$ & $7(15.2)$ & $39(84.8)$ & \\
\hline $36-59$ & $9(13.2)$ & $59(86.8)$ & \\
\hline \multicolumn{4}{|l|}{ Gender } \\
\hline Male & $17(12.7)$ & $117(87.3)$ & \multirow[t]{2}{*}{0.762} \\
\hline Female & $15(14.0)$ & $92(86)$ & \\
\hline \multicolumn{4}{|l|}{ Type of diarrhea } \\
\hline Watery & $8(9.6)$ & $75(90.4)$ & \multirow[t]{2}{*}{ NA } \\
\hline Bloody and mucoid & $24(15.2)$ & $135(84.8)$ & \\
\hline \multicolumn{4}{|l|}{ Onset of diarrhea (days) } \\
\hline 1 & $11(11.8)$ & $82(88.2)$ & \multirow[t]{4}{*}{ NA } \\
\hline 2 & $9(13.8)$ & $54(86.2)$ & \\
\hline 3 & $5(12.8)$ & $34(87.2)$ & \\
\hline $4-14$ & $7(15.9)$ & $37(84.1)$ & \\
\hline
\end{tabular}

diarrhea. The isolates of Shigella also high among children who came to the health center 4-14 days after their onset of diarrhea (Table 1).

\section{Discussion}

The overall prevalence of Shigella in this study was $13.3 \%$ $(32 / 241)$. This was lower than the study conducted in Ethiopia: Jimma in 2001 (20.1 \%) [22], and Gondar in 2009 (31.1\%) [11], but this finding is higher than studies conducted in Ethiopia in 2014: Hawassa (7 \%) [14], Gondar (4.5\%) [15] and Jimma (2.3\%) [16]. Shigellosis seems to be reduced from time to time in Ethiopia as observed from 2001 by Mache [22] to studies conducted in 2014 by Getamsey et al. [14], Demissie et al. [15] and Beyene and Tasew [16].

It is also lower than studies conducted in Eritrea (47.6 \%) [12], Botswana (19.5\%) [20], Nepal (79 \%) [9], North Iran (76.8 \%) [23] and Northeast Malaysia (30.1\%) [24].

Isolates of Shigella were high in the age group of 12-23 months. This might be due to the interest of children to contact with environment at a time of toddling or playing on the ground which may increase the acquisition of Shigella infection [25]. This is similar to the study conducted in Peruvian Amazon [26], Indonesia [27] and other developing countries studied by Platts-Mill, et al. [6]. But, it was different from the study carried out in
Ethiopia: Hawassa in which the isolation rate of Shigella was high among the age group of 36-47 months [14]. The lowest isolation rate of Shigella was shown in the age group of 6-11 months with the prevalence rate of $3.9 \%$. This is comparable to the study conducted in northern Iran [23], but it differs from the study conducted in Ethiopia: Hawassa [14]. No Shigella was isolated from the age group of 0-5 months in this study. This was similar to the epidemiological study conducted in the horn of Africa [28], but it was dissimilar to the finding of the study carried out in Ethiopia: Hawassa [14] and Peruvian Amazon [26].

High prevalence of Shigella was isolated from the study participants whose onsets of diarrhea were between 4 and 14 days. Those diarrheic children who came late to the health center might be developed a serious feature of dehydration, abdominal cramps, even death. They might be potential source to infect other children in the community if they defecate outside the latrine.

\section{Limitation}

This study did not perform the antimicrobial susceptibility patterns, serotypes, risk factors of Shigella and other diarrheal causing agents due to budget constraint.

\section{Conclusion}

There was high prevalence of Shigella in this study. The most affected age group in the present study was 12-23 months. Therefore; parents or guardians, all health professionals particularly health extension workers, governmental and nongovernmental organizations should work hard on public health prevention measures. Further large scale studies also recommended in order to planning appropriate interventions by including possible risk factors associated with shigellosis in under-5 children.

\section{Authors' contributions}

AGK was participated in intellectualizing and designing the study, proposal writing, data collection, data analysis interperation and drafting the initial manuscript. ZT was participated in designing, data analysis, interpretation and critical review of the manuscript. Both authors read and approved the final manuscript.

\section{Author details}

${ }^{1}$ Department of Microbiology and Immunology, Institute of Biomedical Sciences, College of Health Sciences, Mekelle University, P.O. Box: 1871, Mekelle, Tigray, Ethiopia. ${ }^{2}$ Department of Medical Laboratory Sciences, College of Health and Medical Sciences, Haramaya University, P.O.Box. 331, Harar, Ethiopia.

\section{Acknowledgements}

Our best gratitude should be towards Haramaya University, College of Medical sciences, Department of Medical laboratory sciences for their approval of this research to be conducted. We would like to thank Mekelle zone health office for their permission to conduct the research in Mekelle health center and to Mr. Eyob Zigta, Mr. Natnael Berhane, Mr Gebregzieher Berihu, Mrs. Kiros Haile, Mrs. Freweini G/Michael and Ms. Berhan Halefom for their support during sample collection. 


\section{Competing interests}

The authors declare that they have no competing interests.

Received: 23 March 2015 Accepted: 25 November 2015 Published online: 15 December 2015

\section{References}

1. Kotloff KL, Winickoff JP, Ivanoff B, Clemens JD, Swerdlow DL, Sansonetti PJ, et al. Global burden of Shigella infections: implications for vaccine development and implementation of control strategies. Bull World Health Organ. 1999;77(8):651-66.

2. National Shigella surveillance annual report. Atlanta. Georgia: US Department of Health and Human Services, CDC; 2012. p. 2014.

3. European Centre for Disease Prevention and Control. Annual epidemiological report reporting on 2011 surveillance data and 2012 epidemic intelligence data. Stockholm: ECDC; 2013.

4. Von Seidlein L, Kim DR, Ali M, Lee H, Wang XY, et al. A multicentre 176 study of Shigella diarrhea in six Asian countries: disease burden, clinical manifestations, and microbiology. PLoS Med. 2006;3(9):1556-69.

5. Public Health Agency of Canada. National enteric surveillance program annual summary, 2012. Canada: Public Health Agency; 2014.

6. Platts-Mills JA, Babji S, Bodhidatta L, Gratz J, Haque R, Havt A, et al. Pathogen-specific burdens of community diarrhea in developing countries: a multisite birth cohort study (MAL-ED). Lancet Glob Health. 2015;3:564-75.

7. Kotloff KL, Nataro JP, Blackwelder WC, Nasrin D, Farag TH, Panchalingan S, et al. Burden and aetiology of diarrheal disease in infants and young children in developing countries (the Global Enteric Multicenter Study, GEMS): a prospective, case-control study_abstract. Lancet. 2013;382(9888):209-22

8. Wang X, Du L, Seidlein L, Xu Z, Zhang Y, Hao Z, Han O, Ma J, Lee L, Ali M, Han C, Xing Z, Chen J, Clemens J. Occurrence of shigellosis in the young and elderly in rural china: results of a 12-month population-based surveillance study. Am J Trop Med Hyg. 2005;73(2):416-22.

9. Bhattacharya S, Khanal B, Bhattarai NR, Das ML. Prevalence of Shigella species and their antimicrobial resistance patterns in Eastern Nepal. J Health Popul Nutr. 2005;23(4):339-42.

10. Nunes MRCM, Magalhaes PP, Penna FJ, Nunes JMM, Mendes EN. Diarrhea associated with Shigella in children and susceptibility to antimicrobials. J Pediatr. 2012;88(2):125-8.

11. Xia S, Xu B, Huang L, Zhao JY, Ran L, Zhang J, Chen H, Pulsrikarn C, Pornruangwong S, Aarestrup FM, Hendriksen RS. Prevalence and characterization of human Shigella infections in Henan province, China. J Clin Microbiol. 2011;49(1):232-42.

12. Naik DG. Prevalence and antimicrobial susceptibility patterns of Shigella species in Asmara, Eritrea, Northeast Africa. J Microbiol Immunol Infect. 2006:39:392-5.

13. Bercion R, Njuimo SP, Boudjeka PM, Manirakiza A. Distribution and antibiotic susceptibility of Shigella isolates in Bangui, Central African Republic. Trop Med Int Health. 2008;13(4):468-71.

14. Getamesay M, Beyene G, Zeynudin A. Prevalence of Shigella, Salmonella and Campylobacter species and their susceptibility patters among under
5 children with diarrhea in Hawassa town, south Ethiopia. Ethiop J Health Sci. 2014;24(2):101-8.

15. Beyene G, Tasew H. Prevalence of intestinal parasite, Shigella and Salmonella species among diarrheal children in Jimma health center, Jimma southwest Ethiopia: a cross sectional study. Ann Clin Microbiol. 2014;2014(13):10.

16. Demissie AT, Wubie TM, Yehuala FM, Fetene MD, Gudeta AG. Prevalence and antimicrobial susceptibility patterns of Shigella and Salmonella species among patients with diarrhea attending Gondar Town Health Institutions, Northwest Ethiopia. Sci J Pub Health. 2014;2(5):469-75.

17. Tiruneh M. Serodiversity and antimicrobial resistance pattern of Shigella 199 isolates at Gondar University teaching hospital, Northwest Ethiopia. Jpn J Infect Dis. 2009;62:93-7.

18. Giorgi G, Krishan K, Maoulidi M. Health need assessment for Mekelle City, Ethiopia, MCI social sector working paper series, No 6/2009. Millennium Cities Initiatives, Earth Institute, Columbia University.

19. Federal Democratic Republic of Ethiopia (EFDR). Ethiopia: regions, major cities and towns-statistics....-maps on city population. 2011-07. http:// www.citypopulation.de. Accessed 31 Jan 2012.

20. Urio EM, Collison EK, Gashe BA, Sebunya TK, Mpuchane S. Shigella and Salmonella strains isolated from children under 5 years in Gaborone, Botswana, and their antibiotic susceptibility patterns. J Trop Med Int Health. 2001;6(1):55-9.

21. Mikoleit ML. A WHO network building capacity to detect, control and prevent food borne and other enteric infections from farm to table. Laboratory protocol: isolation of Salmonella and Shigella from faecal specimens. Atlanta; 2010.

22. Mache A. Antibiotic resistance and sero groups of Shigella among pediatric outpatients in southwest Ethiopia. East Afr Med J. 2001;78(6):296-9.

23. Ghaemi EO, Aslani MM, Moradi AV, Dadgar T, Livani S, Mansourian AR, Nosrat SB, Ahmadi AR. Epidemiology of Shigella-associated diarrhea in Gorgan, north of Iran. Saudi J Gastroenterol. 2007;13(3):129-32.

24. Singh KB, Ojha SC, Deris ZZ, Rahman RA. A 9-year study of shigellosis in Northeast Malaysia: antimicrobial susceptibility and shifting species dominance. J Public Health. 2011;219(19):231-6.

25. Orrett FA. Prevalence of Shigella serogroups and their antimicrobial resistance patterns is southern Trinidad. J Health Popul Nutr. 2008;26:456-62.

26. Kosek M, Yori PP, Pan WK, Olortegui MP, Gilman RH, Perez J, Chavez CB, Sanchez GM, Burga R, Hall E. Epidemiology of highly endemic multiply antibiotic-resistant shigellosis in children in the Peruvian Amazon. Pediatrics. 2008;122(3):541-9.

27. Agtini MD, Soeharno R, Lesmana M, Punjabi NH, Simanjuntak C, Wangsasaputra F, Nurdin D, Pulungsih SP, Rofiq A, Santoso H, Pujarwoto H, Sjahrurachman A, Sudarmono P, Von Seidlein L, Deen JL, Ali M, Lee H, Kim DR, Han O, Park JK, Suwandono A, Ingerani A, Oyofo B, Campbelle JR, Beecham HJ, Corwin AL, Clemmens JD. The burden of diarrhea, shigellosis, and cholera in north Jakarta, Indonesia finding from 24 month surveillance. BMC Infect Dis. 2005;5:89.

28. World Health Organization. Communicable disease epidemiological profile. Horn of Africa, emergency-affected countries; 2007.

\section{Submit your next manuscript to BioMed Central and we will help you at every step:}

- We accept pre-submission inquiries

- Our selector tool helps you to find the most relevant journal

- We provide round the clock customer support

- Convenient online submission

- Thorough peer review

- Inclusion in PubMed and all major indexing services

- Maximum visibility for your research

Submit your manuscript at www.biomedcentral.com/submit

C BioMed Central 